\title{
Elaboração de um roteiro para avaliação do ambiente e do mobiliário no domicílio de idosos*
}

\section{Developing a roadmap for evaluating environmental and furniture in the home of elderly}

\author{
Luciana Bolzan Agnelli Martinez ${ }^{1}$, Maria Luísa Guillaumon Emmel ${ }^{2}$
}

http://dx.doi.org/10.11606/issn.2238-6149.v24i1p18-27

Martinez LBA, Emmel MLG. Elaboração de um roteiro para avaliação do ambiente e do mobiliário no domicílio de idosos. Rev. Ter. Ocup. Univ. São Paulo. 2013 jan./abr.;24(1):18-27.

RESUMO: As dificuldades apresentadas com o avanço da idade trazem reflexos na manipulação do ambiente, especialmente no domicílio. Os cuidados com a avaliação ambiental são requisitos importantes, porém ainda existem poucas escalas a serem utilizadas no Brasil. O objetivo do trabalho foi elaborar um checklist para avaliar condições espaciais da residência de idosos. O instrumento, elaborado em duas partes, foi testado na residência de 12 idosos, com idade entre 60 e 75 anos, sendo verificadas dificuldades no preenchimento e necessidade de ajustes. O referencial teórico da primeira parte foram os parâmetros da Norma Brasileira de Acessibilidade NBR 9050 (ABNT, 2004), e da segunda parte o questionário adaptado por Ferrer et al. (2004) e as medidas da posição sentada descritas por Chaffin, Anderson e Martin (2001). Os resultados apontam que a versão final do checklist possibilita uma investigação sintética e de fácil preenchimento, que contém dados gerais sobre o ambiente físico (primeira parte) e informações sobre mobiliários e medidas antropométricas do idoso (segunda parte). Além de contemplar temas relevantes, apresenta critérios reconhecidos em acessibilidade, tornando-se uma ferramenta para os profissionais avaliarem aspectos que envolvem segurança e funcionalidade na residência, bem como para direcionar as ações de adequação ambiental.

DESCRITORES: Terapia ocupacional; Ambiente; Avaliação; Meio social; Habitação; Qualidade ambiental; Meio ambiente; Idosos.
Martinez LBA, Emmel MLG. Developing a roadmap for evaluating environmental and furniture in the home of elderly. Rev. Ter. Ocup. Univ. São Paulo. 2013 jan./abr.;24(1):18-27.

\begin{abstract}
Difficulties with advancing age brings reflections on the manipulation of the environment, especially at home. The care of the environmental assessment requirements are important, but there are still a few scales to be used in Brazil. The objective was to develop a checklist to assess spatial conditions of residence for the elderly. The instrument, made in two parts, was tested at the residence of 12 elderly aged 60 and 75 years, and noted difficulties in filling the need for adjustments. The theoretical part of the first were the parameters of the Brazilian Accessibility NBR 9050 (ABNT, 2004), and the second part of the questionnaire adapted by Ferrer et al. (2004) and measures the sitting position described by Chaffin, Anderson and Martin (2001). The results indicate that the final version of the checklist provides a summary investigation and easy filling, which contains general data about the physical environment (first part) and information about securities and anthropometric measurements of the elderly (second part). Besides viewing relevant topics, presents recognized criteria for accessibility, making it a tool for professionals assess aspects involving safety and functionality in residence, and to direct the actions of environmental adaptation.
\end{abstract}

KEY-WORDS: Occupational therapy; Social environmental; Environmental quality; Evaluation; Environment; Housing; Aged.

\footnotetext{
* O artigo se relaciona a uma etapa do projeto para a obtenção do título de mestre por Luciana Bolzan Agnelli, sob a orientação de Maria Luísa Guillaumon Emmel, como parte integrante da dissertação intitulada "Avaliação da acessibilidade do idoso em sua residência", apresentada ao Programa de Pós Graduação em Terapia Ocupacional da UFSCar - Área de concentração: "Promoção do Desenvolvimento Humano nos Contextos da Vida Diária". Apresentação em forma de pôster dos projetos "Elaboração de um roteiro de avaliação para o domicílio de idosos" e "Características dos mobiliários de idosos na posição sentada" no evento: XII Congresso Brasileiro e IX Congresso Latino Americano de Terapia Ocupacional, realizado de 11 a 14 de Outubro de 2011, no Centro de Convenções Frei Caneca na cidade de São Paulo.

Apresentação na modalidade oral do tema “Avaliação do idoso em sua residência”, na Roda de Conversa 6, no II Seminário Nacional de Pesquisa em Terapia Ocupacional, realizado no dia 30 de Outubro de 2012, no Rio de Janeiro.

${ }^{1 .}$ Mestre em Terapia Ocupacional pela Universidade Federal de São Carlos (UFSCar), através do Programa de Pós Graduação em Terapia Ocupacional (PPGTO), na área de concentração: "Promoção do Desenvolvimento Humano nos Contextos da Vida Diária"

2. Professora Associada do Departamento de Terapia Ocupacional da Universidade Federal de São Carlos (UFSCar); Docente do Programa de Pós Graduação em Educação Especial e do Programa de Pós Graduação em Terapia Ocupacional da UFSCar.

Endereço para correspondência: Rua Antônio Carreri, 100, Jardim Ricetti, São Carlos - SP. CEP 13570-070. E-mail: to@luagnelli.com. brou luagnelli@yahoo.com.br
} 


\section{INTRODUÇÃO}

Terapia Ocupacional em Gerontologia
visa a promoção da qualidade de vida,
especialmente através da promoção da independência em atividades cotidianas e da satisfação por parte do idoso ${ }^{12}$. Para tanto é preciso fazer um levantamento de uma série de fatores relacionados ao idoso, que se inicia, segundo Barreto e Tirado ${ }^{6}$, com dados sócio-demográficos e história de vida. Em seguida, as autoras mencionam a avaliação funcional, para o conhecimento de habilidades e limitações, e a avaliação ambiental, que busca identificar problemas e estratégias para maior integração do idoso neste ambiente ${ }^{6}$.

O ambiente está entre os fatores que influenciam a funcionalidade na velhice ${ }^{18,19}$ e deve oferecer, segundo Ribeiro et al. ${ }^{20}$, segurança, estímulos, controle pessoal, interação social, favorecer a adaptação às mudanças e ser familiar ao idoso. Portanto, para que os objetivos da Terapia Ocupacional sejam alcançados, muitas vezes fazse necessária a intervenção direta no ambiente físico, a fim de favorecer a manutenção da capacidade funcional, independência e autonomia do idoso ${ }^{12}$.

Considerando desde o ambiente imediato do indivíduo até o ambiente geral, a Classificação Internacional de Funcionalidade, Incapacidade e Saúde (CIF) considera que as características do mundo físico, social e de atitude têm um impacto facilitador ou limitador sobre os componentes da funcionalidade e da incapacidade, não apenas nas condições de saúde, mas também nas atividades e na participação em diferentes situações. Dessa forma, a sociedade pode restringir o desempenho das pessoas ao oferecer um ambiente com barreiras ou simplesmente quando não fornece facilitadores necessários para o desempenho de uma determinada tarefa ${ }^{16}$. Segundo Atwal ${ }^{4}$, "os terapeutas ocupacionais têm um papel importante na remoção das barreiras ambientais". Mas, como propõe a CIF, não se trata apenas da eliminação de barreiras arquitetônicas, pois os locais acessíveis devem apresentar facilitações, ou seja, ajudas técnicas que precisam ser incluídas no ambiente.

Diante da necessidade de se garantir acessibilidade nas edificações, mobiliário, espaços e equipamentos urbanos, a Associação Brasileira de Normas e Técnicas (ABNT) criou a Norma Brasileira (NBR) 9050, estabelecendo parâmetros técnicos a serem observados desde o projeto e construção, ou então na adequação de ambientes já existentes ${ }^{1}$. A primeira norma brasileira publicada foi em 1985, ainda com lacunas, tendo passado por revisões e reformulações que culminaram com a publicação de uma nova versão, em 2004, contemplando aspectos antes não mencionados.
Entre os pressupostos adotados em 2004 e revisados em 2005, estão: acessibilidade, desenho universal, barreira arquitetônica e tecnologia assistiva, incluindo também: dimensões necessárias para a circulação de pessoas em diferentes condições; referências para alcance manual e visual; formas de comunicação e sinalização (piso tátil e braille); especificações de equipamentos eletrônicos; dimensionamento de rampas; escadas; banheiros; entre outras informações. Após se consolidar como um referencial técnico em acessibilidade e em virtude da credibilidade da ABNT, verifica-se o uso da NBR 9050 como instrumento confiável, com critérios mínimos para ambientes acessíveis, quanto ao conforto e funcionalidade ${ }^{7}$.

Para ambientes coletivos, portanto, esta norma tem sido o principal referencial para a elaboração de instrumentos de avaliação, como por exemplo, para o acesso de pessoas com limitações físicas a serviços de saúde $^{24}$, para escolas públicas de ensino fundamenta ${ }^{11} \mathrm{e}$ para Bibliotecas ${ }^{15}$.

Além da promoção direta da funcionalidade, a adaptação do ambiente domiciliar pode prevenir quedas em idosos ${ }^{14}$. Perracini e Gazzola ${ }^{18,19}$ afirmam que a avaliação ambiental é fundamental não apenas quanto ao risco de quedas, mas também devido ao risco de intoxicações, queimaduras, choques e outras lesões, sendo que o uso de tecnologias têm contribuído para a minimização de tais riscos.

De acordo com Andrade e Pereira ${ }^{3}$, em um estudo de revisão bibliográfica, sobre a influência da tecnologia assistiva em idosos frágeis, as evidências científicas concluem que o uso de recursos tecnológicos permite ao idoso, em muitos casos, desenvolver atividades funcionais com segurança, aumentando sua independência e autonomia, além de diminuir a necessidade de cuidadores, evitar hospitalizações e institucionalizações, contribuindo, dessa forma, para a manutenção de funções motoras e cognitivas, interação social e melhoria da qualidade de vida.

O cuidado com a avaliação é um dos requisitos para aumentar a segurança e o terapeuta ocupacional tem sido o profissional escolhido para coordenar este processo. A avaliação ambiental pode ser feita por entrevistas e observação direta, podendo ser dividida em: avaliação dos componentes pessoais, avaliação dos componentes ambientais e análise das problemáticas relacionadas à acessibilidade do local ${ }^{8}$.

Segundo Barreto e Tirado ${ }^{6}$, o ambiente físico deve ser observado em sua arquitetura (parede, piso, desníveis, iluminação, ventilação, circulação) e quanto às características do mobiliário, como disposição e quantidade. Ao analisar especificamente o ambiente domiciliar, 
Cavalcanti e Galvão ${ }^{8}$ consideram importantes os seguintes critérios: mobilidade (dimensões do espaço para as tarefas), orientabilidade (se o meio apresenta informações para o acesso e funcionalidade) e usabilidade (interação entre o indivíduo e os equipamentos do ambiente).

Diante de uma proposta de atuação tão abrangente do terapeuta ocupacional com a população idosa, uma série de aspectos precisam ser avaliados para que a intervenção seja eficiente. Nessa perspectiva as escalas e instrumentos de avaliação podem ser utilizados para favorecer a coleta de dados e facilitar a documentação de informações relevantes.

Através de um teste padronizado, o profissional estabelece uma linha de base bem definida, sobre a qual podem basear suas decisões. Portanto faz-se necessária a criação de novos instrumentos, tanto para a clínica como para a pesquisa, de forma que as medidas sistematizadas em saúde garantam a comparabilidade de resultados ${ }^{17}$.

De um modo geral, há escassez de instrumentos de avaliação no Brasi ${ }^{25}$. Chaves et al. ${ }^{9}$ realizaram uma revisão de literatura e constataram que existem poucas escalas de avaliação em Terapia Ocupacional que podem ser utilizadas no país. Além disso, "as escalas já validadas e/ou elaboradas em português encontradas avaliam o desempenho ocupacional sob diferentes aspectos". Dessa forma, faltam instrumentos de avaliação voltados para o ambiente domiciliar, que auxiliem no mapeamento das condições de acesso na residência, que facilitem a identificação dos aspectos que necessitam de intervenção.

O objetivo do estudo foi criar um roteiro de avaliação ambiental do tipo checklist, de aplicação rápida e objetiva, para a identificação das condições espaciais favoráveis e desfavoráveis na residência de idosos.

\section{PROCEDIMENTOS METODOLÓGICOS}

A pesquisa apresentou caráter exploratório, pois buscou o primeiro contato com o tema a ser pesquisado. Procurou-se realizar a caracterização e o agrupamento dos aspectos relevantes do ambiente físico no domicílio do idoso, visando a criação de um roteiro de avaliação específico para isto, como parte da pesquisa desenvolvida por Agnelli ${ }^{2}$.

O trabalho foi realizado junto aos alunos do programa Universidade Aberta da Terceira Idade (UATI) e foi submetido e aprovado pelo Comitê de Ética em Pesquisa envolvendo Seres Humanos da Universidade Federal de São Carlos, estando de acordo com as exigências contidas na resolução 196/96 do Conselho Nacional de Saúde, conforme o parecer de número 220/2010. Além disso, foi obtida autorização formal da UATI para a realização da pesquisa e todos os participantes assinaram um Termo de Consentimento Livre e Esclarecido.

Para a definição da amostra foram adotados critérios cronológicos nacionais, considerando os 60 anos como limite etário para a terceira idade, seguindo limite de idade estabelecido pela Organização Mundial da Saúde (OMS) para os países em desenvolvimento e mesmo limite etário adotado pela Política Nacional do Idoso. O trabalho considerou, para a seleção dos participantes, o primeiro grupo do período de vida aqui estabelecido como velhice, que pode ser classificado, por alguns gerontologistas, como idoso jovem (até 75 anos).

A técnica de amostragem utilizada foi a Amostra Aleatória Simples (AAS), sem reposição. Bastante preciso, este é um dos tipos de amostragem probabilística mais utilizado, cuja seleção é realizada com base num processo em que todos os elementos da população têm a mesma probabilidade de pertencerem à amostra.

Dessa forma, dentre os matriculados com idade entre 60 e 75 anos, foram sorteados aleatoriamente, através de programa estatístico, doze idosos. Destes, dois não quiseram participar, sendo realizado novo sorteio, através da mesma técnica, obtendo-se mais dois nomes, que aceitaram fazer parte do trabalho.

\section{Processo de construção e adequação do checklist}

O roteiro elaborado, em um modelo de checklist, foi testado na residência de 12 idosos, no período de janeiro a abril de 2011. Ao longo destas visitas, foram verificadas as dificuldades no preenchimento e a necessidade de supressão de itens.

Inicialmente havia sido elaborado um checklist com 8 aspectos a serem verificados: 1) Área de circulação livre; 2) Transições (para os cômodos); 3) Piso; 4) Comandos e Controle; 5) Comunicação/sinalização; 6) Presença de facilitadores; 7) Mobiliários; 8) Medidas antropométricas. Como cada um destes temas estava organizado em uma tabela própria, contendo diversos subitens, a avaliação de cada cômodo demandava muito tempo, uma vez que o ambiente físico apresenta muitos detalhes e sofre variações de uma casa para outra.

A supressão de alguns itens ("Piso", "Comandos e Controle" e "Comunicação/sinalização") permitiu focalizar aspectos mais relevantes. Os subitens dos grupos de informação retirados foram parcialmente absorvidos por outros temas. Para facilitar a verificação do local e possibilitar melhor comparação dos dados, as informações foram compactadas e organizadas através de alternativas a serem assinaladas. 
Além disso os cômodos da casa, que estavam dispostos em colunas, foram organizados por página, obtendo-se uma tabela semelhante para cada cômodo, composta por 4 linhas contendo grandes temas de investigação e respectivos subitens distribuídos em 4 colunas. As informações detalhadas do mobiliário mais utilizado pelo idoso foram organizadas em uma outra página, juntamente com as medidas antropométricas.

Sendo assim, o checklist foi dividido em duas partes, o que facilitou a aplicação e organizou melhor as informações registradas. A Primeira delas é destinada aos dados gerais sobre o ambiente físico da casa, com três principais temas de investigação: 1) Área de circulação livre; 2) Transição e passagem; 3) Presença de facilitadores. A Segunda Parte contempla as informações do "Mobiliário" e as "Medidas Antropométricas".

\section{Primeira Parte - Avaliação Ambiental}

Foi adotada como referencial teórico a Norma Brasileira de Acessibilidade - NBR 9050: "Acessibilidade a edificações, mobiliário, espaços e equipamentos urbanos", especialmente no que diz respeito às dimensões do espaço e medidas recomendadas para passagens, bem como algumas características da área de circulação.

O parâmetro utilizado para a avaliação da área de circulação, ilustrado na Figura 1, aponta as dimensões referenciais para o deslocamento de uma pessoa em pé: sem qualquer dispositivo auxiliar para marcha (mínimo de $60 \mathrm{~cm}$ ), com uma bengala (mínimo de $75 \mathrm{~cm}$ ) e com andador (mínimo de 90cm).

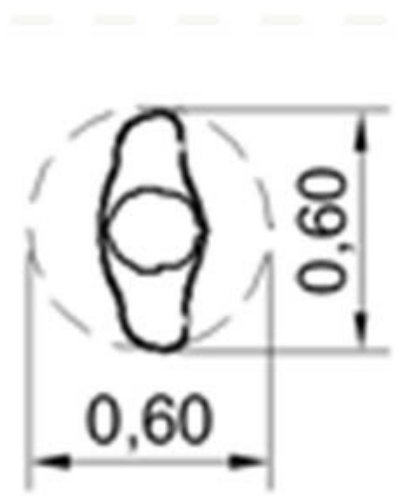

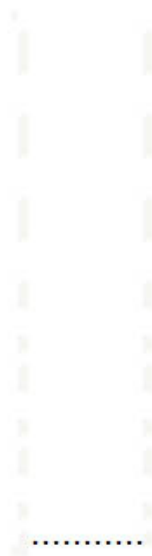
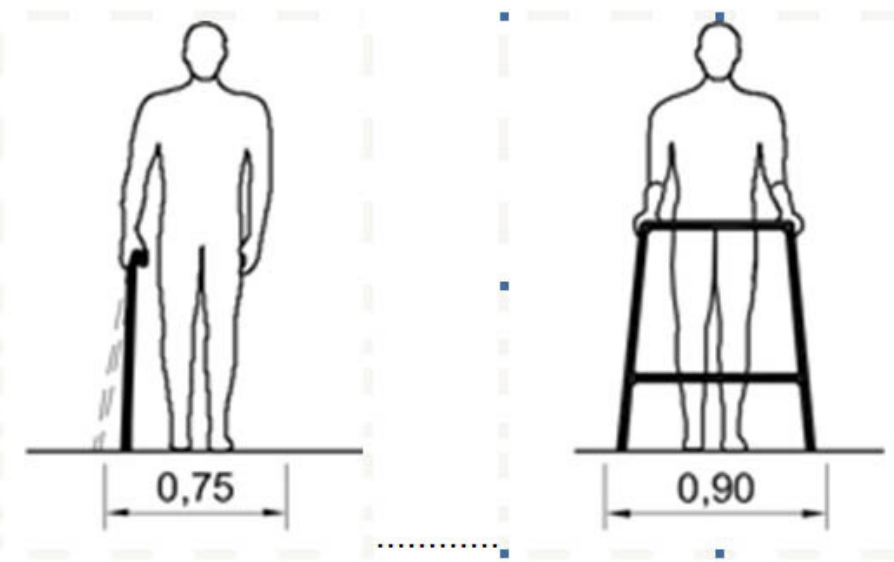

Figura 1 - Dimensões referenciais para o deslocamento em pé (Fonte : Norma 9050, ABNT, 2004)

A partir desse referencial, o roteiro apresenta um campo destinado ao registro das medidas de passagens e portas com menos de $90 \mathrm{~cm}$, a fim de se obter um panorama da área de circulação da residência e identificar situações críticas, como por exemplo, as passagens menores que $75 \mathrm{~cm}$ ou, até mesmo, com menos de $60 \mathrm{~cm}$. Esses critérios foram adotados para os espaços que compreendiam as rotas de acesso dos idosos, não sendo consideradas, portanto, as passagens que não faziam parte do seu percurso diário e cotidiano.

O preenchimento do roteiro elaborado, como se recomenda, também torna possível verificar as possibilidades que o domicílio apresenta para o deslocamento de uma pessoa em cadeira de rodas, cujo módulo de referência apresenta largura de $80 \mathrm{~cm}$ para o equipamento e, portanto, largura mínima de $90 \mathrm{~cm}$ para a circulação, obtendo-se, dessa forma, um retrato da acessibilidade nas situações em que houver algum tipo de dificuldade e/ou necessidade deste equipamento, seja temporária ou definitiva.

Foram consideradas as informações que a Norma propõe a respeito das portas, não apenas quanto à exigência de um vão livre mínimo de $80 \mathrm{~cm}$, mas também em relação às maçanetas, que devem ser do tipo alavanca, e de sua altura, que pode variar de $90 \mathrm{~cm}$ a $1,10 \mathrm{~m}$ do chão. Nesse caso, além das alternativas quanto às medidas das passagens entre os cômodos, foram acrescentadas alternativas quanto ao tipo de maçaneta e um campo para o registro de sua altura.

Quanto ao piso do banheiro admite-se que haja 
um desnível máximo de $1,5 \mathrm{~cm}$ entre o piso do boxe e o restante do sanitário. Para degraus isolados e escadas (dois ou mais degraus) foi utilizado o referencial de que os pisos (profundidade) devem ter entre 28 e $32 \mathrm{~cm}$, ao passo que os espelhos (altura) entre 16 e $18 \mathrm{~cm}$, de forma que altura e profundidade devem ser constantes em toda a escada. $\mathrm{O}$ checklist recomenda que seja assinalada a presença de escadas e/ou degraus, que estes sejam medidos e que os dados obtidos sejam analisados de acordo com o referencial adotado.

O roteiro também contempla alternativas referentes aos obstáculos na área de circulação. A NBR ressalta que os tapetes devem ser evitados em rotas acessíveis e os capachos devem ser embutidos no piso e nivelados, de maneira a não exceder $5 \mathrm{~mm}$. Carpetes e forrações devem ter as bordas fixadas ao piso e devem ser aplicados de maneira a evitar enrugamento da superfície.

Para a análise de barras de apoio e corrimãos, quando presentes, as alternativas do roteiro foram organizadas a partir do parâmetro da empunhadura, preconizando que estes acessórios devem ter seção circular, sem arestas vivas, com diâmetro entre $3,0 \mathrm{~cm}$ e $4,5 \mathrm{~cm}$, bem como estarem firmemente fixadas, a uma distância mínima de $4 \mathrm{~cm}$ entre estas e a face interna da barra.

\section{Segunda Parte - Avaliação do Mobiliário e}

\section{Medidas Antropométricas}

Foi utilizado como referencial o questionário adaptado por Ferrer et al, em 2004, sobre o risco de quedas no domicílio dos idosos, mais especificamente no que diz respeito à tabela que contém as informações do mobiliário que o idoso mais utiliza ou dos mobiliários que se deseja avaliar. De um modo geral a tabela apresenta alternativas quanto à frequência e situações de uso do mobiliário, satisfação do idoso, dificuldades nas transferências, possibilidades de ajustes e medidas do móvel.

Uma tabela que registra as medidas do idoso foi introduzida nesta segunda parte do roteiro a fim de verificar se os mobiliários avaliados estão adequados para cada usuário e identificar o que poderia ser modificado. $\mathrm{O}$ principal referencial teórico adotado para este conteúdo foram as medidas antropométricas na posição sentada descritas por Chaffin, Anderson e Martin (2001).

\section{Análise dos juízes}

Ao final das 12 visitas domiciliares, o roteiro elaborado foi enviado por e-mail para 12 profissionais de áreas afins, que foram convidados a serem juízes, dos quais 8 responderam, dentre eles: 2 professores do Departamento de Terapia Ocupacional da UFSCar; 1 terapeuta ocupacional especialista em Gerontologia; 2 terapeutas ocupacionais da área de Tecnologia Assistiva; 1 terapeuta ocupacional da área de Ergonomia; 1 arquiteta da área de Acessibilidade e 1 profissional da área de Estatística.

O parecer foi enviado ao pesquisador por e-mail, em formulário previamente elaborado, de forma que, após o conhecimento dos objetivos da pesquisa, analisaram 6 aspectos, pontuando de 0 ("muito ruim") a 5 ("muito bom") quanto a: conteúdo, tamanho do roteiro, ordem dos ítens (sequência), organização e clareza das questões, validade e confiabilidade. O trabalho considerou a validade de conteúdo, que diz respeito ao "grau com que um instrumento realmente mede a variável que pretende medir", e como confiabilidade a impressão dos juízes quanto à coerência do roteiro, estabilidade e constância dos resultados ${ }^{13}$

As pontuações dos 8 juízes foram comparadas, calculando-se a média e o desvio padrão para cada aspecto avaliado, conforme a Figura 2.

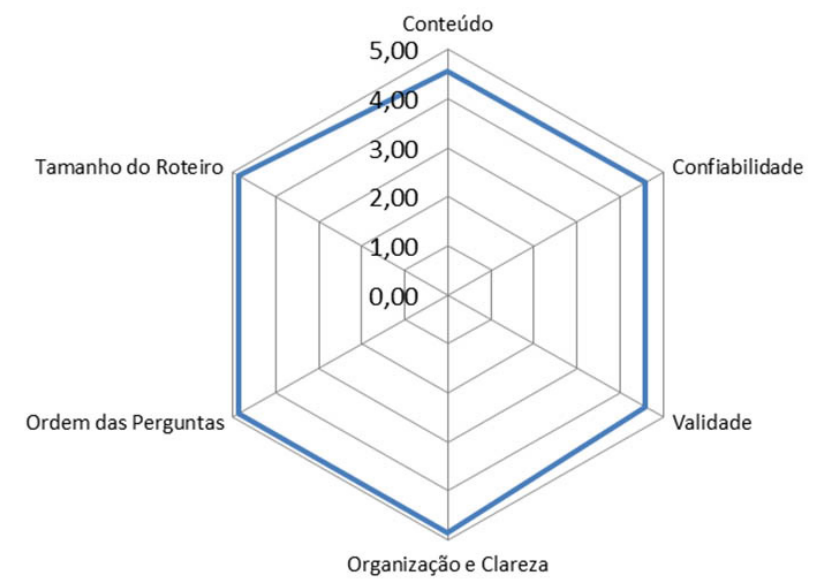

Figura 2 - Gráfico radar ilustrando a avaliação dos juízes

Diante de algumas sugestões que foram apresentadas, $\mathrm{o}$ instrumento passou por pequenos ajustes, consolidando o processo de elaboração e de validade de conteúdo.

\section{RESULTADOS}

Após a elaboração descrita na metodologia e as sugestões fornecidas pelos juízes, a versão final do checklist contemplou temas relevantes de uma avaliação ambiental, de maneira sintética e de fácil preenchimento. 
Após a supressão de itens, as informações foram reestruturadas em 5 grupos: 1) Área de circulação livre; 2) Transição e passagem (para os cômodos); 3) Presença de facilitadores; 4) Mobiliários; 5) Medidas antropométricas.

Os três primeiros grupos foram organizados em uma única página, obtendo-se uma tabela única, e compuseram a Primeira Parte - Avaliação Ambiental (Tabela 1). Esta tabela é composta por 3 linhas, contendo os três temas de investigação, e seus subitens foram distribuídos em 4 colunas.

Tabela 1 - Primeira Parte - Avaliação Ambiental (Fonte: Agnelli, 2012)²

\begin{tabular}{|c|c|c|c|c|}
\hline \multicolumn{5}{|c|}{ CÔMODO: } \\
\hline \multirow[b]{2}{*}{$\begin{array}{c}\text { ÁREA DE } \\
\text { CIRCULAÇÃO } \\
\text { DO IDOSO }\end{array}$} & $\begin{array}{l}\text { Passagens com } \\
\text { menos de } 90 \mathrm{~cm} \text { ?* }\end{array}$ & Piso & Desníveis & Presença de obstáculos \\
\hline & Medidas: & $\begin{array}{l}\text { ( ) plano } \\
\text { ( ) com vãos } \\
\text { ( ) com buracos } \\
\text { ( ) inclinado } \\
\text { Ângulo: } \\
\text { ( ) mudança de textura/ } \\
\text { tipo de piso } \\
\text { ( ) colorido } \\
\text { ( ) escorregadio*** }\end{array}$ & $\begin{array}{l}\text { ( ) degrau } \\
\text { Altura: } \\
\text { ( ) escada**** } \\
\text { Altura de cada degrau: }\end{array}$ & $\begin{array}{l}\text { ( ) vaso ( ) fio } \\
\text { ( ) outros: } \\
\text { Tapetes: } \\
\text { ( ) Soltos } \\
\text { ( ) Embutidos } \\
\text { ( ) Nivelados***** } \\
\text { ( ) Bordas fixadas } \\
\text { ( ) Anti-derrapante }\end{array}$ \\
\hline \multirow[b]{2}{*}{$\begin{array}{l}\text { TRANSIÇÃO } \\
\text { OU } \\
\text { PASSAGEM } \\
\text { PARA }\end{array}$} & Largura* & Maçaneta & Desníveis & Passagem coberta? \\
\hline & $\begin{array}{l}\text { Medida: } \\
\text { ( ) menos de } 75 \mathrm{~cm} \\
\text { ( ) entre } 75 \text { e } 90 \mathrm{~cm} \\
\text { ( ) mais de } 90 \mathrm{~cm}\end{array}$ & $\begin{array}{l}\text { ( ) alavanca } \\
\text { ( ) giratória } \\
\text { ( ) outro tipo } \\
\text { Altura da maçaneta ao } \\
\text { piso: }\end{array}$ & $\begin{array}{l}\text { ( ) degrau } \\
\text { Altura: } \\
\text { ( ) escada**** } \\
\text { Altura de cada degrau: } \\
\text { ( ) mudança de textura/ } \\
\text { tipo de piso }\end{array}$ & $\begin{array}{l}\text { ( ) sim } \\
\text { ( ) não } \\
\text { OBS: }\end{array}$ \\
\hline \multirow[b]{2}{*}{$\begin{array}{c}\text { PRESENÇA } \\
\text { DE FACILITA- } \\
\text { DORES }\end{array}$} & Barra de apoio & Corrimão & $\begin{array}{c}\text { Sinalização de } \\
\text { informações }\end{array}$ & Outros \\
\hline & $\begin{array}{l}\text { Quantas: } \\
\text { ( ) fixação estável } \\
\text { ( ) seção circular } \\
\text { ( ) diâmetro }<3 \mathrm{~cm} \\
\text { ( ) entre } 3,0 \mathrm{e} \\
4,5 \mathrm{~cm} \\
\text { ( ) }>4,5 \mathrm{~cm}\end{array}$ & $\begin{array}{l}\text { ( ) fixação estável } \\
\text { ( ) seção circular } \\
\text { ( ) diâmetro }<3 \mathrm{~cm} \\
\text { ( ) entre } 3,0 \text { e } 4,5 \mathrm{~cm} \\
(\text { ) }>4,5 \mathrm{~cm}\end{array}$ & $\begin{array}{l}\text { ( ) visual } \\
\text { ( ) tátil } \\
\text { ( ) sonora } \\
\text { ( ) informativa }\end{array}$ & $\begin{array}{l}\text { ( ) Interruptor perto da } \\
\text { cama } \\
\text { ( ) luz de emergência } \\
\text { ( ) tapete anti-derrapante } \\
\text { ( ) cadeira de banho } \\
\text { ( ) banco } \\
\text { ( )elevação do sanitário } \\
\text { ( ) outros: }\end{array}$ \\
\hline
\end{tabular}

* ABNT 9050 deslocamentos: pessoa em pé c/ uma bengala - mínimo de $75 \mathrm{~cm}$; pessoa em pé c/ andador - mínimo de $90 \mathrm{~cm}$

**O ângulo da inclinação será medido através de clinômetro

***Escorregadio - neste caso se o idoso julga escorregadio

**** Considera-se escada dois ou mais degraus

*****Tapetes nivelados - apresentam diferença menor do que $5 \mathrm{~mm}$ do chão $(>5 \mathrm{~mm}=$ desnível $)$

Os demais temas de investigação, "Mobiliários" e "Medidas Antropométricas", foram organizados em outra página, através de duas tabelas independentes (Tabelas
2 e 3), uma para cada assunto, compondo, dessa forma, a Segunda Parte - Avaliação do Mobiliário e Medidas Antropométricas. 
MARTINEZ, L. B. A.; EMMEL, M. L. G. Elaboração de um roteiro. Rev. Ter. Ocup. Univ. São Paulo. 2013 jan./abr.;24(1):18-27.

Tabela 2 - Segunda Parte - Mobiliário (Fonte: Agnelli, 2012)²

\begin{tabular}{|c|c|c|c|c|}
\hline \multicolumn{5}{|c|}{ MOBILIÁRIO: } \\
\hline Freqüiência de uso & Situações de uso & $\begin{array}{l}\text { Dificuldade na } \\
\text { atividade assinalada }\end{array}$ & $\begin{array}{l}\text { Sente-se bem neste } \\
\text { mobiliário? }\end{array}$ & Acha perigoso?* \\
\hline $\begin{array}{l}\text { ( ) menos de } 5 \mathrm{~h} / \mathrm{dia} \\
\text { ( ) de } 5 \text { a } 8 \mathrm{~h} / \mathrm{dia} \\
\text { ( ) mais de } 8 \mathrm{~h} / \mathrm{dia}\end{array}$ & $\begin{array}{l}\text { ( ) descanso } \\
\text { ( ) refeição } \\
\text { ( ) lazer (ex: TV, } \\
\text { crochê) } \\
\text { ( ) Outros }\end{array}$ & $\begin{array}{l}\text { ( ) sim } \\
\text { ( ) não } \\
\text { Por quê? }\end{array}$ & $\begin{array}{l}\text { ( ) sim } \\
\text { ( ) não } \\
\text { Por quê? }\end{array}$ & $\begin{array}{l}\text { ( ) sim } \\
\text { ( ) não } \\
\text { Por quê? }\end{array}$ \\
\hline $\begin{array}{l}\text { Possibilidade de } \\
\text { ajustes }\end{array}$ & $\begin{array}{l}\text { Dificuldade para se } \\
\text { sentar? }\end{array}$ & $\begin{array}{l}\text { Dificuldade para se } \\
\text { levantar? }\end{array}$ & $\begin{array}{l}\text { Precisa de apoio em } \\
\text { outros locais? }\end{array}$ & $\begin{array}{l}\text { Estes locais já } \\
\text { se moveram, } \\
\text { inclinaram ou } \\
\text { balançaram? }\end{array}$ \\
\hline $\begin{array}{l}\text { ( ) sim } \\
\text { ( ) não } \\
\text { Quais: }\end{array}$ & $\begin{array}{l}\text { ( ) } \operatorname{sim}(\text { ) não } \\
\text { ( ) tempo maior do } \\
\text { que antes }\end{array}$ & $\begin{array}{l}\text { ( ) } \operatorname{sim} \text { ( ) não } \\
\text { ( ) tempo maior do que } \\
\text { antes }\end{array}$ & $\begin{array}{l}\text { ( ) sim ( ) não } \\
\text { Aonde: }\end{array}$ & ( ) sim ( ) não \\
\hline $\begin{array}{l}\text { Ângulo assento- } \\
\text { encosto** }\end{array}$ & Assento & Encosto & Apoio para os braços & Observações \\
\hline $\begin{array}{l}\text { ( ) menor que } 90^{\circ} \\
\text { ( ) } 90^{\circ} \\
\text { ( ) maior que } 90^{\circ} \\
\text { ( ) Não aplicável }\end{array}$ & $\begin{array}{l}\text { Altura: } \\
\text { Largura: } \\
\text { Profundidade: }\end{array}$ & $\begin{array}{l}\text { ( ) não ( ) sim } \\
\text { Altura: } \\
\text { Largura: }\end{array}$ & $\begin{array}{l}\text { ( ) não ( ) sim } \\
\text { Altura: } \\
\text { Largura: } \\
\text { Profundidade: }\end{array}$ & \\
\hline
\end{tabular}

* Segundo Ferrer (2004) o móvel é perigoso quando se mover, balançar, deslocar inesperadamente ou oferecer algum risco de tropeço

**Medida com goniômetro

Tabela 3 - Segunda Parte - Medidas Antropométricas (Fonte: Agnelli, 2012)²

Parte 2 - MEDIDAS DO IDOSO

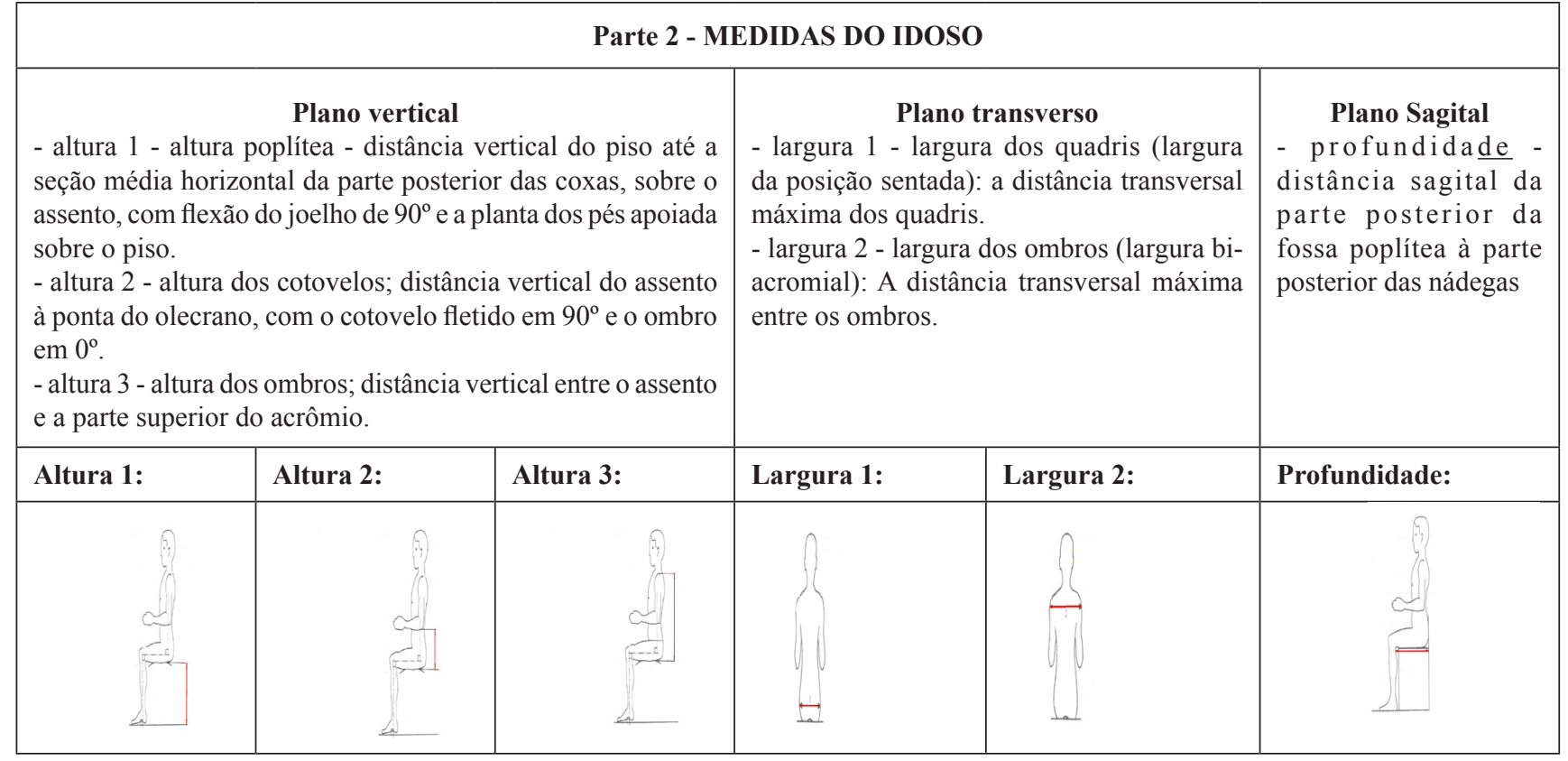


Para padronizar as informações e facilitar o preenchimento foram acrescentadas, na segunda tabela da parte 2, a descrição e a imagem de cada medida a ser realizada.

Como o roteiro é composto por apenas duas partes compactas, pode ser aplicado em quantos cômodos ou mobiliários forem necessários, de forma prática e objetiva. Cada página deverá ser reproduzida de acordo com a necessidade: a quantidade de cômodos e o número de mobiliários a serem avaliados na residência irão determinar o número de cópias para a aplicação da Primeira e da Segunda Parte do instrumento, respectivamente. O roteiro pode ser aplicado por completo ou em apenas uma de suas partes, a depender do interesse do profissional ou pesquisador.

\section{DISCUSSÃO}

A NBR 9050 foi criada para a adequação de ambientes públicos e privados de uso coletivo. No entanto, como os critérios utilizados para sua construção consideram aspectos ergonômicos e medidas antropométricas, puderam ser utilizados como referência para a construção de um roteiro para a avaliação do domicílio.

Para a determinação das dimensões referenciais para o deslocamento, foram consideradas pela ABNT as medidas entre $5 \%$ a $95 \%$ da população brasileira, ou seja, "os extremos correspondentes a mulheres de baixa estatura e homens de estatura elevada". A norma considera, portanto, os valores médios da população brasileira quanto a estatura e porte físico. Por este motivo, faz-se necessário, sempre que possível, uma avaliação das características individuais antes de qualquer decisão ou intervenção. Dessa forma, para algumas situações, como por exemplo, para a análise das medidas de mobiliários, quando se tratar de um ambiente particular, é recomendado que a avaliação seja individualizada, motivo pelo qual foi criada uma tabela específica no checklist para isso. Portanto, para se avaliar, por exemplo, a adequação da altura da cama, das cadeiras ou do vaso sanitário da residência, o mais indicado será considerar as medidas de cada pessoa que ali reside, o que não será possível quando se tratar de ambientes coletivos, devendo-se, neste caso, seguir as medidas apresentadas pela ABNT.

Especificamente em relação à área de circulação dos cômodos, o roteiro construído traz informações que serão analisadas de acordo com a NBR 9050, possibilitando identificar, por exemplo, estreitamentos dos espaços de circulação. Na população idosa, isto pode representar um alerta, principalmente se for considerada a possibilidade do uso de uma bengala, situação que exige o mínimo de $75 \mathrm{~cm}$ de passagem livre. A situação pode ser ainda mais crítica se a pessoa necessitar de andador ou de cadeira de rodas, para os quais se recomenda, respectivamente, $80 \mathrm{e}$ $90 \mathrm{~cm}$ de passagem.

Portanto, o roteiro elaborado, ao quantificar e mensurar todas as passagens da casa que apresentam menos do que $90 \mathrm{~cm}$, proporciona informações importantes no presente momento e permite uma projeção para o futuro, caso um dos participantes venha a utilizar algum dos dispositivos auxiliares para deslocamento.

Realizar uma avaliação ambiental sem estabelecer parâmetros poderia comprometer a interpretação dos resultados e dificultar a comparação e correlação entre os dados. Se tomarmos como exemplo o primeiro tema que compõe o roteiro ("Área de Circulação"), foi considerado o espaço mínimo de circulação encontrado dentro de cada cômodo, segundo os critérios da Norma 9050², independentemente do tamanho do cômodo, área construída e número de mobiliários dispostos. Isso porque uma casa pequena com móveis bem organizados pode ter uma área maior para a circulação livre do que uma residência ampla com muitos obstáculos.

Para que a coleta de informações seja completa e precisa, recomenda-se o uso do roteiro construído associado a outros questionários ou métodos de avaliação, a depender da finalidade que se deseja. No caso do ambiente físico, recomenda-se o uso de instrumentos de medição, como trena comum ou trena à laser, goniômetro (para verificar o ângulo entre o assento e o encosto nos mobiliários) e clinômetro, caso o piso seja inclinado ou para a medição do ângulo de inclinação de rampas.

Além disso, é importante ressaltar que o checklist aqui proposto favorece o processo de avaliação dos aspectos físicos do ambiente, podendo, por este motivo, ser aplicado com outras faixas etárias.

Diante disso, considera-se importante a abordagem de componentes pessoais, como o comportamento, a percepção e a relação da pessoa com o ambiente. Dessa forma, o roteiro de avaliação aqui apresentado, assim como outros instrumentos de coleta, precisam ser usados com finalidades específicas e não devem substituir avaliações não padronizadas e aspectos subjetivos, tanto em relação ao ambiente quanto aos demais aspectos a serem avaliados.

Sempre que possível faz-se necessária a participação do idoso e de sua família, de forma que tenham oportunidade de se expressar. Seria interessante que o próprio morador pudesse apontar, por exemplo, locais que acha perigosos ou ainda o que ele considera um elemento facilitador no ambiente físico de sua casa. 
Dessa forma, apesar da opção pelo aspecto físico da avaliação ambiental, o trabalho possibilitou uma discussão a respeito do ambiente domiciliar em sua ampla definição, como um conjunto de dimensões físicas, sociais, culturais, organizacionais e institucionais, podendo influenciar direta ou indiretamente na saúde e bem-estar do idoso. O terapeuta ocupacional deve atentar para a variedade de alternativas de adequação ambiental que, no aspecto físico, por exemplo, abrangem desde modificações simples, como a mudança de localização dos tapetes (que antes eram objetos de decoração e agora podem representar risco de acidentes) até a necessidade de algumas alterações que implicam em reformas estruturais.

Cabe ressaltar que o presente artigo apresentou a geração de itens e a composição do instrumento de avaliação, bem como sua formatação. Contudo novos estudos precisam ser realizados para verificar se o instrumento é realmente confiável e válido para a finalidade a qual foi elaborado. Além disso, estão recomendados, neste caso, procedimentos estatísticos para o cálculo dos índices de fidedignidade e para mensurar a consistência interna do instrumento ${ }^{21}$.

\section{CONCLUSÕES}

O roteiro elaborado à partir da NBR $9050^{1}$ contemplou temas relevantes de uma avaliação ambiental, de forma sintética e de fácil preenchimento, e contém parâmetros

\section{REFERÊNCIAS}

1. Associação Brasileira de Normas e Técnicas. NBR 9050: Acessibilidade a edificações, mobiliário, espaços e equipamentos urbano. Rio de Janeiro, 2004.

2. Agnelli LB. Avaliação da acessibilidade do idoso em sua residência [Dissertação]. São Carlos: Universidade Federal de São Carlos, Programa de Pós-Graduação em Terapia Ocupacional; 2012.

3. Andrade VS, Pereira LSM. Influência da tecnologia assistiva no desempenho funcional e na qualidade de vida de idosos comunitários frágeis: uma revisão bibliográfica. Rev Bras Geriatr Gerontol (Rio de Janeiro). 2009;12(1):113-22.

4. Atwal A. Patologias da velhice In: Atwal A, McIntyre A. Terapia ocupacional e a terceira idade. São Paulo: Santos; 2007. p.67-97.

5. Barros CFM. Casa segura: uma arquitetura para a maturidade [citado 21 fev. 2012]. Disponível em: http://www.casasegura. reconhecidos na área de Acessibilidade.

Embora as determinações da norma estejam relacionadas a ambientes coletivos, trazendo, dessa forma, medidas padrão e considerações sobre design universal, alguns de seus critérios, relacionados à ergonomia e acessibilidade, também puderam ser considerados diante da análise de ambientes particulares, constituindo um importante referencial técnico para a avaliação ambiental no domicílio de idosos, especialmente no que diz respeito à área de circulação livre e presença de desníveis/obstáculos. É necessário, nestes casos, adequar os parâmetros utilizados pela $A B N T$ às particularidades do indivíduo em questão.

As demandas do idoso apresentam-se diferentes das outras fases da vida, sendo necessário ampliar os estudos e as estratégias da Terapia Ocupacional com esta população, bem como as formas de avaliação e os instrumentos de coleta de informações. Especificamente em relação ao ambiente físico, foi possível elaborar uma ferramenta para a avaliação de aspectos importantes para a segurança e funcionalidade do idoso na residência.

O checklist ambiental apresentado pode ser facilmente utilizado por terapeutas ocupacionais e por outros membros da equipe, possibilitando rápida identificação de barreiras ou de facilitadores no ambiente domiciliar. Poderá ser usado como ferramenta para direcionar o olhar do profissional e do próprio idoso para estratégias e modificações que podem ser realizadas no ambiente, bem como ações que podem ser desenvolvidas para a prevenção e para a promoção de independência. arq.br.

6. Barreto KML, Tirado MG. Terapia ocupacional em gerontologia. In: Freitas EV, et al. Tratado de geriatria e gerontologia, Rio de Janeiro: Guanabara Koogan; 2006. p.1210-5.

7. Calado GC, Elali GA. Acessibilidade no ambiente escolar: reflexões com base no estudo de duas escolas municipais de Natal-RN [Dissertação]. Natal: Universidade Federal do Rio Grande do Norte, Programa de Pós-Graduação em Arquitetura e Urbanismo; 2006.

8. Cavalcanti A, Galvão C. Adaptação ambiental e doméstica. In: Cavalcanti A, Galvão C. Terapia ocupacional: eundamentação e prática. Rio de Janeiro: Guanabara Koogan; 2007. p.420-6.

9. Chaves GFS, et al. Escalas de avaliação para terapia ocupacional no Brasil. Rev Ter Ocup Univ São Paulo. 2010;21(3):240-6. 
10. Fabrício SCC, Rodrigues RAP, Junior MLC. Causas e consequências de quedas de idosos atendidos em hospital público. Rev Saúde Pública. 2004;38(1):93-9.

11. Kasper AA, et al. Acessibilidade espacial escolar em pátios para alunos com restrições visuais: a construção de um instrumento de avaliação. Rev Progr Pós-Grad Arquit Urban FAUUSP (São Paulo). 2009;16(25):292-307.

12. Lopez PB. Terapia ocupacional em geriatria: 15 casos práticos. Madrid: Panamericana; 2002.

13. Martins GA. Sobre confiabilidade e validade. Rev Bras Gestão Negócios (São Paulo). 2006;8(20):1-12.

14. Mello MAF. Terapia ocupacional gerontológica. In: Cavalcanti A, Galvão, organizadores. Terapia ocupacional: fundamentação e prática, Rio de Janeiro: Guanabara Koogan; 2007. p.49-54.

15. Nicoletti TF, Moro ELS. Acessibilidade em bibliotecas. In: $7^{\circ}$ Senabraile - Bibliotecas: espaços Acessíveis a Múltiplos Usuários, UNICAMP, Campinas, SP, nov. 2011.

16. OMS/OPAS Classificação Internacional de Funcionalidade e Incapacidade e Saúde, CIF. São Paulo: EDUSP; 2003.

17. Paixão Junior CM, Reichenheim ME. Uma revisão sobre instrumentos de avaliação do estado funcional do idoso. Cad Saúde Pública (Rio de Janeiro). 2005;21(1):7-19.

18. Perracini MR, Fló CM, Guerra RO. Funcionalidade e Envelhecimento. In: Perracini MR, Fló CM, organizadores. Funcionalidade e envelhecimento: fisioterapia: teoria e prática clínica. Rio de Janeiro: Guanabara Koogan; 2009. p.3-24.

19. Perracini MR, Gazzola JM. Avaliação Multidimensional do idoso. In: Perracini MR, Fló CM, organizadores. Funcionalidade e envelhecimento: fisioterapia: teoria e prática clínica. Rio de Janeiro: Guanabara Koogan; 2009. p.25-53.

20. Ribeiro AP, et al. A influência das quedas na qualidade de vida de idosos. Ciênc Saúde Coletiva (Rio de Janeiro). 2008;13(4):1265-73.

21. Raymundo VP. Construção e validação de instrumentos: um desafio para a psicolinguística. Letras Hoje (Porto Alegre). 2009;44(3):86-93.

22. Rocha FL, Cunha UG,V. Aspectos psicológicos e psiquiátricos das quedas do idoso. Arq Bras Med (Rio de Janeiro). 1994;68(1):9-13.

23. Silva TM, et al. A vulnerabilidade do idoso para as quedas: análise dos incidentes críticos. Rev Eletr Enf (Goiânia). 2007;9(1):64-78 [citado 29 mar. 2013]. Disponível em: http:// www.fen.ufg.br/revista/v9/n1/v9n1a05.htm.

24. Vasconcelos LR, Pagliuca LMF. Mapeamento da acessibilidade do portador de limitação física a Serviços Básicos de Saúde. Esc Anna Nery Rev Enferm (Rio de Janeiro). 2006;10(3):494-500.

25. Sisto FF, Pacheco L. Estudo exploratório para construção de um instrumento de ajustamento social. Psicol Estud (Maringá). 2002;7(2):83-90. 